\title{
Evaluation of a Health-Management Course for Recently Settled Immigrants
}

\author{
Rita Sjöström ${ }^{1}$ (D) Gunilla Kaev ${ }^{2}$ (D) $\cdot$ Lars Söderström $^{3}$ iD
}

Accepted: 30 March 2021/Published online: 31 May 2021

(C) The Author(s) 2021

\begin{abstract}
This study aims to evaluate an intervention, consisting of nine weeks of healthmanagement course, combined with social and working life orientation and language instruction for recently settled immigrants in Sweden. One hundred one participants in the intervention groups and 48 participants in the control group participated. The intervention consisted of a health management course combined with social and working life orientation and the control group participated in the regular local authority program for social and working life orientation. Measurement instruments were health-related quality of life (HRQoL) and registration of work rate. Several participants in the groups were in work, primarily in subsidized employment, after six months. Recently settled men were employed to a greater extent than the women, where poorer physical and mental health could be observed among women in this study. Participants in the intervention and the control groups had maintained HRQoL from pre-intervention to six months post-intervention. More studies investigating the participants experiences of the healthmanaging course but also more homogenous measurements in studies for recently settled immigrants are needed.
\end{abstract}

Keywords Civic orientation $\cdot$ Health promotion school $\cdot$ Health-related quality of life Migration $\cdot$ Recently arrived

Rita Sjöström

rita.sjostrom@umu.se; rita.sjostrom@ regionjh.se

1 Department of Community Medicine and Rehabilitation, Unit of Research, Education and Development, Östersund, Umeå University, Östersund Hospital, Building 12, 3d floor, 83127 , Östersund, Sweden

2 The Coordination Agency of the Region of Jämtland, Östersund, Sweden

3 Unit of Research, Education and Development, Östersund Hospital, Östersund, Sweden 


\section{Introduction}

Research shows that recently settled refugees self-report poorer health than people born in Sweden. This applies to both physical and mental health (Swedish National Board of Health and Welfare, 2009). There is a strong link between ill health and participation in society and health is consequently a crucial issue for integration (Lindencrona, 2008). It is therefore important to give individuals tools and knowledge to empower them to affect their own lives and thus become established in society. Health promotion perspectives based on understanding of the conditions of migration should be developed as policy for implementing introduction programs, and collaboration among government agencies should be increased. This was adopted as the approach for the Coordination Agency's developmental work in 2015-2017, which was called HAM-SAM, an acronym derived from the Swedish words for Health, Jobs, Migration, and Collaboration. As a concept, HAM-SAM comprises two parts: (1) an intervention focused on health ("health-management course") which is delivered by primary care staff in the national health service and in collaboration with (2) expanded social and labor market knowledge/orientation, delivered by project managers attached to local authority integration offices (The Coordination Agency of the Region of Jämtland, 2014).

As an intervention, the HAM-SAM health-management course was developed in harmony with models developed and lessons learnt based on a program in Malmö, in southern Sweden (Eriksson-Sjöö et al., 2012; Eriksson-Sjöö \& Ekblad, 2009). A theoretical explanatory model called the "Health Arrow" (Lindencrona et al., 2006) developed based on the work of Silove (1999), Ekblad and Silove (1998), and McLeroy et al. (1988) is the basis for a health school (Eriksson-Sjöö, 2012). The model is based on five levels of intervention (policy, community, organizational, interpersonal, and individual) and five health systems (attachment, safety/security, identity/roles, human rights/justice, and existential/creation of meaning). According to Eriksson-Sjöö et al., 2012), putting the theoretical explanatory model into practice as a health school requires certain fundamental principles to be fulfilled, such as establishing interpersonal contact among the participating individuals in the group, which encourages communication and understanding. As well, group activities must be structured in time, space, content, and form. It is important that various professions with experience in the Swedish healthcare system participate in the health school and that group leaders have experience with/understanding of group dynamics and processes (Eriksson-Sjöö et al., 2012).

The aim of this study was to evaluate an intervention consisting of nine weeks of health-management course, combined with social and working life orientation and language instruction for recently settled immigrants in need of additional support in or after the introduction/establishment process: before (pre-intervention) and at the end of the health-management course (post-intervention) and six months after its completion (six months post-intervention).

The research questions were (1) How was self-reported health-related quality of life (HRQoL) affected from pre-intervention to six months post-intervention? (2) Was there any difference between women and men in self-reported HRQoL from pre-intervention to six months post-intervention? (3) How was the work rate affected from pre-intervention to six months post-intervention? and (4) Was there any difference between the percentage of women and men in work from pre-intervention to six months post-intervention? 


\section{Methods}

The study was a pilot study comprising two intervention groups (which received standard of care offered by regular local authority and a health-management course) and one control group (which received standard of care offered by regular local authority). Data were collected between November 2015 and October 2017. Ethical approval was obtained from the Regional Ethical Review Board, Umeå (Ref. 2015/411-31Ö).

\section{Study Groups}

\section{Intervention Groups}

Participants in the intervention groups were recently settled male and female immigrants in need of additional support during or after the two-year introduction/ establishment process. The Public Employment Service and the Social services cooperated and captured the individuals who seemed to have slow progress in the vicinity of the labor market or studies. It was not a medical assessment that was made primarily to receive the offer of participation in a health course. It was intended as a strengthening and preventive factor in the individual's life situation with the goal of entering the labor market, absorbing language, and orienting themselves in the new society as a migrant. It was voluntary to accept the offer to participate in the health course.

The women and men who participated lived in two municipalities in Jämtland County, Strömsund and Åre. These women and men were offered the healthmanagement course delivered by primary care professionals. The participants were recruited to the health course via the Public Employment Service. The Public Employment Service ran the introduction/establishment program jointly with the local authorities. None of the participants from Åre were in work when they began the health course, but some participants from Strömsund were in work.

\section{Control Group}

Participants in the control group were recently settled male and female immigrants living in Berg, a municipality in Jämtland County, where they were participating in the regular local authority program for social and working life orientation and language instruction. The participants were recruited via the Public Employment Service in Berg. Some participants from Berg were in work and others were participating in the social and working life orientation program.

\section{Instrument}

\section{Health-Related Quality of Life Survey (RAND-36)}

The Short Form 36-Item Survey is one of the most commonly used instruments for assessing health-related quality of life (HRQoL). Two identical versions of the original instrument are currently available: the public domain, license free RAND- 
36 and the commercial SF-36. RAND-36, a standardized self-administered instrument for measuring HRQoL was used in this study, where the aim was to measure HRQoL and change over time. RAND-36 assesses eight health concepts with multi-item scales: physical functioning, role limitations caused by physical health problems, role limitations caused by emotional problems, social functioning, emotional well-being (mental health), energy/fatigue (vitality), pain, and general health perceptions. The RAND-36 scales are added to arrive at two summary health indices (summary scores) for physical health (physical functioning, role limitations caused by physical health problems, pain and general health perceptions) and mental health (role limitations caused by emotional problems, social functioning, emotional well-being and energy/fatigue), which provide an overall picture of HRQoL (Orwelius et al., 2017; Rand Health Care, 2018).

The scales are scored using the Likert method, which involves summing responses with equal weight. The scoring generates values from 0 to 100 , where higher values indicate better HRQoL (Orwelius et al., 2017; Rand Health Care, 2018).

\section{Registration of Work Rate}

Staff responsible for social and working life orientation in the local authorities registered the work rate for all participants in the intervention and control groups (Swedish Social Insurance Agency, 2015) based on a form called the Multisector System for Tracking Collaboration and Financial Coordination in Rehabilitation. The alternative work rate levels were $100 \%, 75 \%, 50 \%, 25 \%$, or $0 \%$ of full-time work.

\section{Procedure}

\section{Intervention Groups}

Participants in the intervention groups answered the RAND-36 self-administered survey at the start and end of the health-management course (meetings 1 and 9) and six months after the end of the health course. Language support or phone interpreters were available to participants when completing the RAND-36 selfadministered survey. Work rate was registered pre-intervention and six months post-intervention (Fig. 1). About two months elapsed between measurements 1 and 2 and six months between 2 and 3. There were no structured activities via HAM-SAM, the health-management course, for the participants between measurement 2 and 3.

$\boldsymbol{\nabla} \quad$ 9-week health school

(2 months)
(6 months)

End

6 months

Start

Measurement 2

\section{Measurement 3}

Fig. 1 Design of the intervention, self-administered RAND-36 survey (HRQoL) (measurements 1, 2, and 3) and registration of work rate (measurements 1 and 3 ) 


\section{Control Group}

When participants in the control group began the module for discussion of health perspectives in the municipal social and working life orientation program, they answered the RAND-36 survey (Orwelius et al., 2017; Rand Health Care, 2018). The self-administered RAND-36 survey was also completed at the last meeting of the health discussion component and six months after the end of the program. Language support was available on-site when participants answered the survey. Work rate was registered at the start and six months after the end of social and working life orientation.

The authors did not participate actively in either the intervention or control groups but participated as observers at some points in the intervention group. However, the authors had regular contact with the staff of both the intervention and control groups for discussion and feedback on how it worked with challenges and strengths of the programs in both groups. Nothing was adjusted during the study in the intervention or control groups.

\section{Social and Working Life Orientation}

The participants in the intervention and control groups participated in social and working life orientation and language instruction provided by the local authority. The education for recently settled male and female immigrants in the different municipalities may differ depending on how the teaching has been organized. In the groups in this study, the education in social and working life orientation has been based on the book "About Sweden." The book deals with topics like to come to Sweden, to live in Sweden, to earn a living and support families and to grow in Sweden, individual rights and obligations, to start a family and live with children in Sweden, to influence in Sweden, to care for one's health, and to grow older in Sweden. In addition to the education based on the book "About Sweden," the participants in the intervention groups had the opportunity to deepen social orientation around health linked to working life. Language instruction is offered to all recently settled immigrants, Swedish for Immigrants (SFI), and aims to give adults, with a mother tongue other than Swedish, basic knowledge of the Swedish language.

\section{Health-Management Course}

\section{Intervention Groups}

In addition to social and working life orientation and language instruction provided by the local authority, the participants took part in an intervention, a "health-management course," that included theoretical and practical modules and whose purpose was to give participants theoretical knowledge and tools that can be used in daily life to regain or maintain improved health. Both the theoretical and practical components of the health school were delivered in easy Swedish, without interpreters. Glossaries were used for each theme to enhance learning. The glossaries were covered in the social and working life orientation classes. The discussions were held in Swedish.

The health-management course, five to ten participants per group, began with an introductory meeting, followed by seven meetings in groups (women/men) that covered theoretical and practical instruction, and a final meeting. The participants met once 
a week for about two hours. The health course meetings were held in each municipality and the health course team included various professions from the primary care and the dental services. Themes in the health-management course included health, anatomy and physiology with the help of a human torso model, types of diet, alcohol, and tobacco. Registered nurses (district nurses) instructed also topics about self-care, among other things visits to the local pharmacy. Physical activity was performed by a physiotherapist. The physiotherapist informed about self-training and ergonomics. Health information was provided by a midwife with a focus on reproductive health, sex and cohabitation, contraception, and about genital diseases. Oral health was presented by a dental hygienist and a dental nurse. Mental and social health with sleep hygiene, relationships, stress, attitude, and behavior was discussed together with a primary care counselor and psychologist. Walking or Nordic walking (Nordic walking is fitness walking with specially designed poles similar to ski poles) as well as relaxation was performed every occasion.

\section{Control Group}

Participants in the control group participated in a local authority social and working life orientation program that included five health-related sessions of two to three hours each, with themes like those in the health-management course for the intervention group. Information was delivered and discussions moderated in the health-related sessions by two employees of the local authority integration unit, one of whom was a registered midwife, and the other was an integration coordinator but the control group did not have the same level of professional instruction as the intervention group. Language support was used at these sessions.

\section{Data Analysis}

Data were presented as numbers and, in relevant cases, as percentages, mean and median values, and standard deviations. The results of the RAND-36 self-administered survey were processed as mean values and are presented primarily in graphical form. A linear model covering the municipality and measurement point has been adopted, where coupled differences have been estimated using contrasts. The significance level was 5\% and data were analyzed using SAS version 9.4 (SAS Institute Inc., Cary, NC, USA).

\section{Results}

\section{General}

The results of this study are based on 101 participants in two intervention groups and 48 participants in one control group. The immigrants came from different countries with different languages and different backgrounds in terms of culture, religion, schooling and education, professional careers, family size but also how many in the family have had the opportunity to come to Sweden. Background data for the intervention and control groups are presented in Table 1. 
Table 1 Background variables in intervention groups and control group, number of women and men and (\%), age (mean and $\pm \mathrm{SD}$ ), nationalities (n), and non-response (n)

\begin{tabular}{llll}
\hline & Strömsund $(n=47)$ & Åre $(n=54)$ & Berg $(n=48)$ \\
\hline Women & $23(49)$ & $25(46)$ & $25(52)$ \\
Men & $24(51)$ & $29(54)$ & $23(48)$ \\
Age & $33.1(11.9)$ & $33.8(8.9)$ & $33.7(10.9)$ \\
Nationalities & $12^{*}$ & $3^{*}$ & $5^{*}$ \\
Non-response & 4 & 2 & 3 \\
\hline
\end{tabular}

*Syria, Afghanistan, Somalia, Eritrea, Sudan, Congo Kinshasa, Republic of Uzbekistan, Tajikistan, Turkey, Hungary, Belarus, Thailand, Philippines

Thirteen percent of the participants in Strömsund, 9\% in Åre, and 29\% in Berg had no schooling in their home countries. Most of the participants who had no schooling were women and came from Afghanistan and African countries. The participants were 20 to 56 years old $($ median $=41)$.

Several participants did not participate in the six months post-intervention followup: three women and one man in Strömsund, two men in Åre, and three women in Berg. The participants had moved away from their respective municipalities and could not be reached for a follow-up.

\section{Health-Related Quality of Life Survey (RAND-36)}

\section{Physical and Mental Health Index}

Based on the RAND-36 self-administered HRQoL survey and the summary score for physical health, all three groups (Strömsund, Åre, and Berg) reported maintained physical health from pre-intervention to six months post-intervention (Fig. 2). There was significant difference in the summary score for physical health immediately post-intervention $(p<0.01)$ and at six months post-intervention $(p<0.03)$ between the participants in Åre and Berg and between the participants in Åre and Strömsund pre-intervention $(p<0.03)$.

In the summary score for mental health, the groups from Strömsund and Berg reported a tendency to improved mental health from pre-intervention to six months post-intervention, while the participants from Åre reported maintained mental health during the same period of time (Fig. 3). There was a significant difference between participants in Strömsund and Berg in the summary score for mental health preintervention $(p<0.02)$.

\section{Health Scales}

Among the participants in the intervention group from Åre, there was a tendency towards higher perceived HRQoL for the health scales of physical functioning, role physical, pain, and vitality from pre-intervention to six months post-intervention compared to the intervention group from Strömsund and the control group in Berg. 


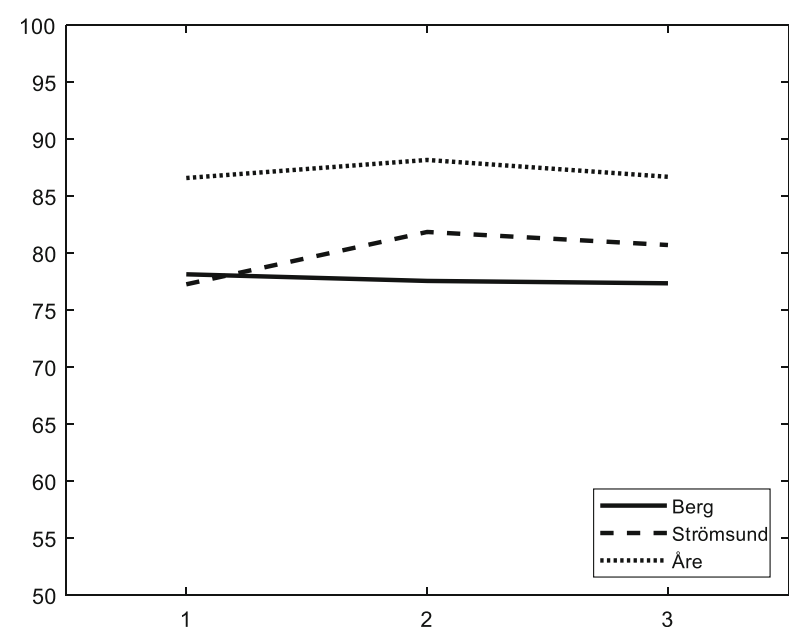

Fig. 2 The development of the health index for physical health among the intervention and control groups before and after the health schoool and 6 months after its completion

In the physical health scales (physical functioning, role physical, pain, and general health), the health scores were reported at the same level from preintervention to six months post-intervention among the participants in both the intervention and control groups.

In the mental health scales, participants in Strömsund and Berg reported maintained health in three of the four scales (energy/fatigue, social functioning, and emotional well-being) but reported a tendency towards improved health in the role emotional scale from pre-intervention to six months post-intervention. Participants from Åre reported maintained mental health in the four health scales from pre-intervention to six months post-intervention.

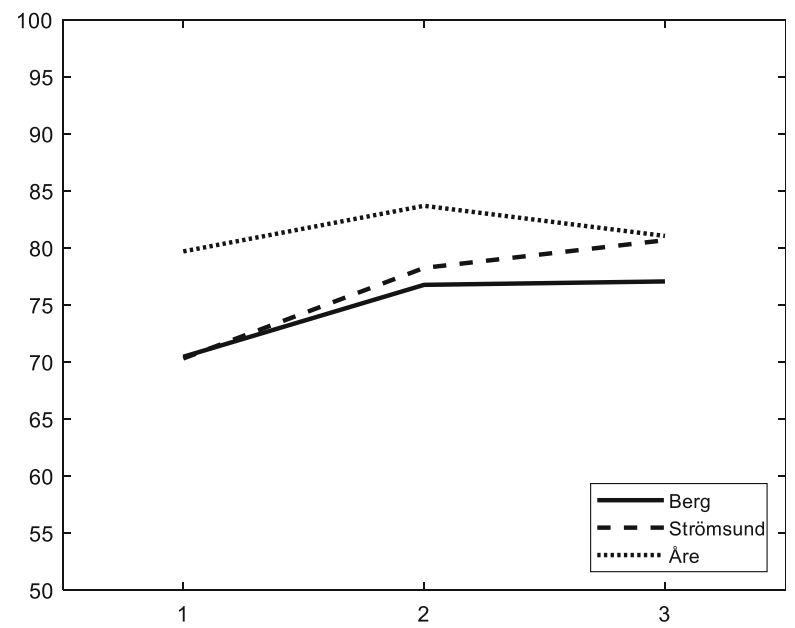

Fig. 3 The development of the health index for mental health among the intervention and control groups before and after the health schoool and 6 months after its completion 


\section{Differences Between Women and Men}

The women reported a tendency towards generally lower self-reported physical (Fig. 5) and mental (Fig. 7) health compared to the men (Figs. 4, 5, and 6) in both the intervention and control groups pre-intervention, post-intervention, and six months post-intervention. However, the women in the Åre intervention group reported significantly higher mental health $(p<0.01)$ in all health scales pre-intervention compared to the women in the other groups (Fig. 7).

Women in both the intervention and control groups generally reported the highest self-reported physical (Fig. 5) and mental (Fig. 7) health in all health scales post-intervention. There was a tendency among the men towards the highest self-reported physical (Fig. 4) and mental (Fig. 6) health at six months post-intervention.

\section{Registration of Work Rate}

Table 2 shows the results of registration of work rate among participants in the intervention and control groups. The table also specifies whether the participants were in subsidized employment or not (Table 2). Subsidized employment, (called "extra jobs" in Sweden) is work with earnings provided by an employer, who receives financial support or subsidy by the Swedish Public Employment Service, for the creation and maintenance of the employment position).

In the Strömsund intervention group, one man was in work pre-intervention. None of the women were in work. At six months post-intervention, seven men and three women were in work. In Åre, no participants were in work pre-intervention, while 17 men and nine women were in work six months post-intervention. In the control group, seven men and three women were in work pre-intervention and 14 men and four women were in work six months post-intervention.

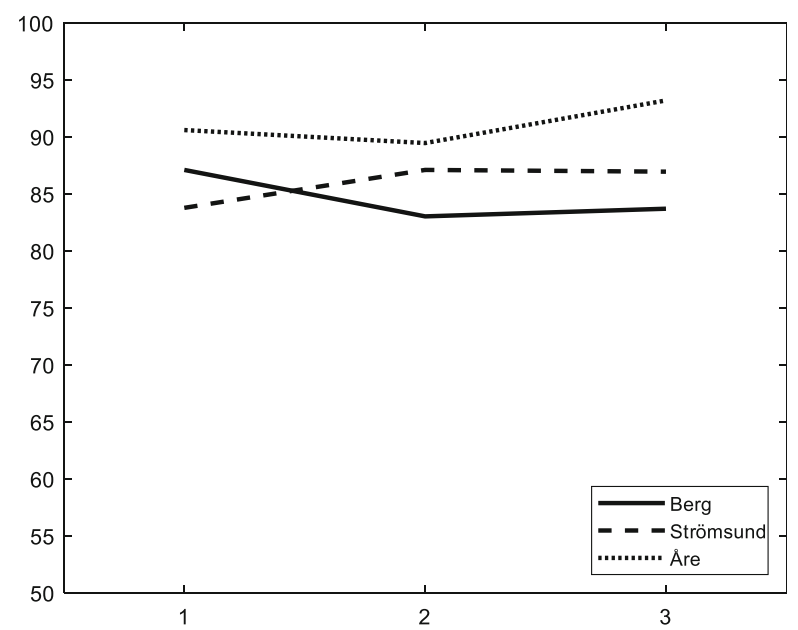

Fig. 4 The development of the physical health scores for men in the intervention and control groups before and after the health school and 6 months after its completion 


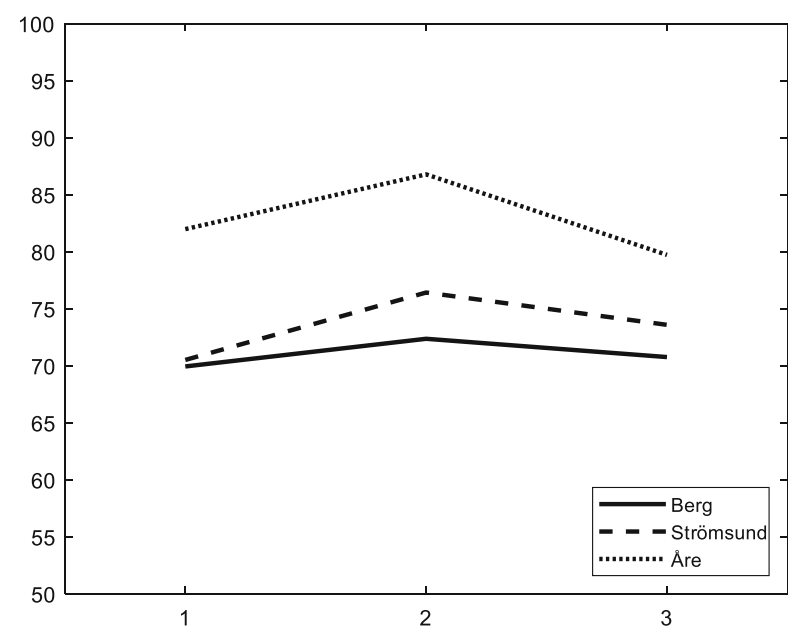

Fig. 5 The development of the physical health scores for women in the intervention and control groups before and after the health school and 6 months after its completion

\section{Discussion}

The results of the study showed that the participants in both the intervention groups and the control group had maintained HRQoL from pre-intervention to six months postintervention and that there was a tendency in some health scales towards higher HRQoL. Several participants in the intervention groups and the control group were in work, primarily in subsidized employment, after six months.

The health course for the intervention groups was designed in two modules, the health course alongside expanded social and labor market studies. The two modules were synchronized and co-planned. The goal, based on the theoretical explanatory model called the "Health Arrow," was to achieve a stronger effect of the five intervention levels and the five health systems described by Lindencrona et al. (2006). Putting

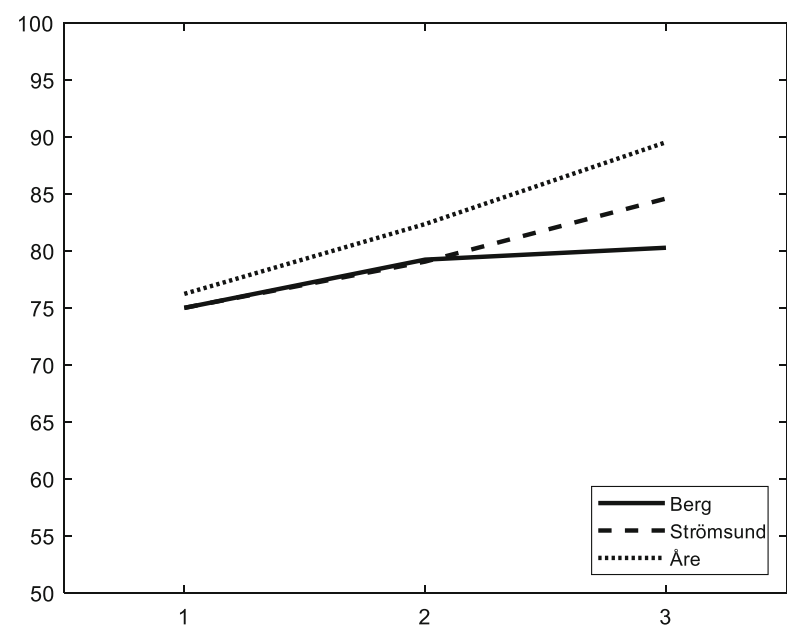

Fig. 6 The development of the mental health scores for men in the intervention and control groups before and after the health school and 6 months after its completion 


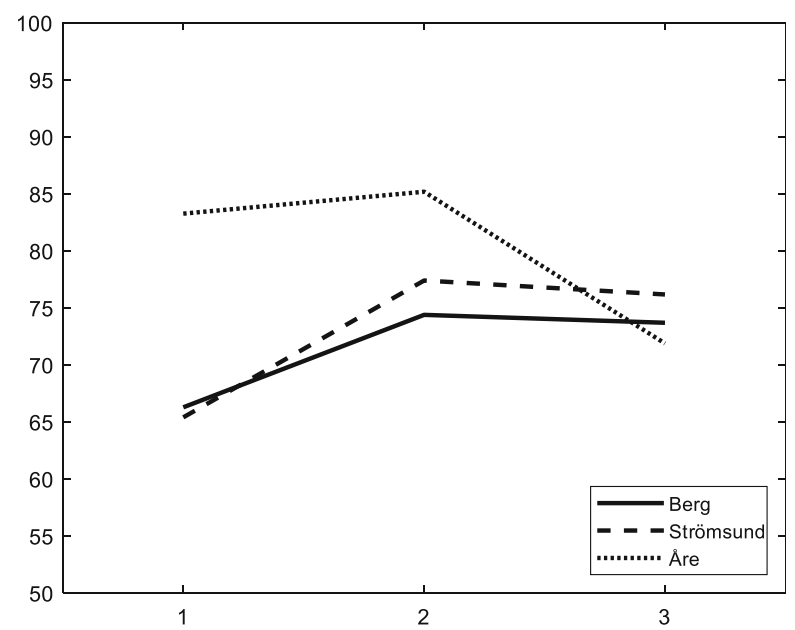

Fig. 7 The development of the mental health scores for women in the intervention and control groups before and after the health school and 6 months after its completion

the theoretical explanatory model into practice as a health course requires certain fundamental principles to be fulfilled according to the explanatory model (Lindencrona et al., 2006). In order to uphold quality and encourage a sense of security in the group, the importance of group leaders having experience and understanding of group dynamics and processes was emphasized. Not least importantly, this can contribute to upholding democratic principles in group communications, that is, in practice, to assure equality and everyone's right to express themselves. In this way, social values based on the principles of the UN Declaration of Human Rights are communicated and practiced at the group and individual levels (United Nations, 1948).

Among the health-management course participants, it proved highly important to be given fact-based information about physical and mental health and to find their own coping strategies based on the theoretical and practical elements in the health course meetings. These involved, for example, the opportunity to take a position in areas related to the body, health, values, and especially mental health. Knowledge about basic things, such as human conception, varied widely among the group, as did views on talking openly about psychological well-being from an individual perspective as well as a gender perspective. Involving professionals who provided fact-based information combined with adapted dialogues and practical elements, as well as gaining access to tools for relaxation and physical activity and improving language skills in order to express themselves about their health and well-being, could be likened to group therapy with a psychoeducational approach. Personal understanding and knowledge of how physical health and mental health are related is also a way of giving participants independent capacity to manage their situations and help alleviate worry and the sense of helplessness. A health-management course run in this way, combined with the extended and parallel social and working life orientation program, based on the same principles and likewise a part of the model based on the Health Arrow by Lindencrona et al. (2006) is a way of balancing experiences that often entail a sense of intense fear, terror, and helplessness. In the long run, group activities according to the HAM-SAM model in terms the health management course and the social and 


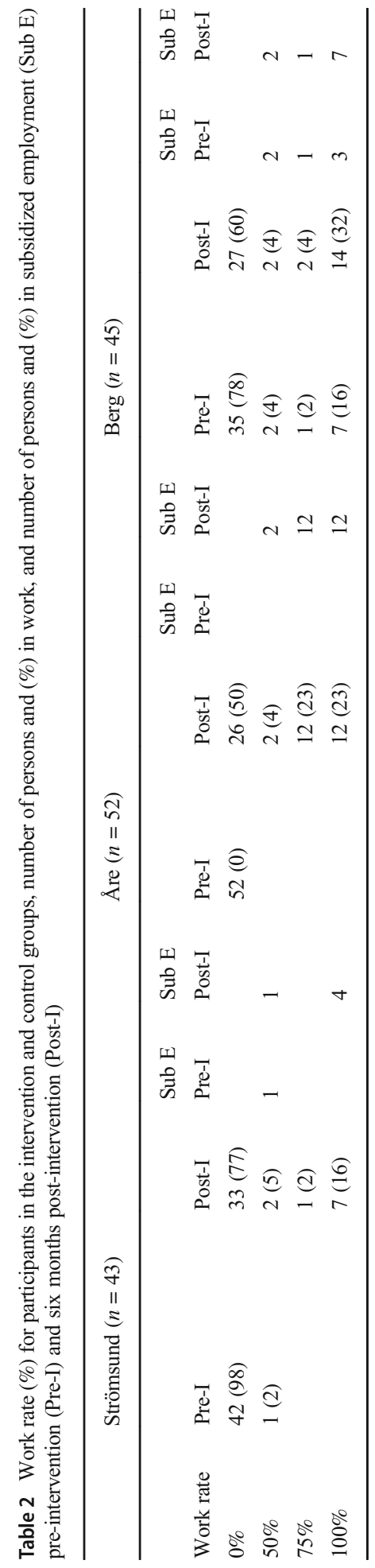


working life orientation program constitute an opportunity for people exposed to stress caused by migration to improve mental health and gain improved quality of life which contributes to social integration.

Among the participants in both intervention groups and the control group, the summary health index for physical HRQoL was assessed as maintained from preintervention to six months post-intervention, while there was a tendency towards improved mental HRQoL for the groups in Strömsund and Berg during the same period of time. Results from other studies in which a health school/course or indepth health information was used as a method, the school or information were evaluated using various self-administered surveys or interviews and it is difficult to compare the results due to the heterogeneity (Forsen et al., 2010). Just as in this study, participants in other studies report maintained or improved HRQoL after having participated in a health school/course or health information. There was no appreciable difference in the assessment of HRQoL or work rate among the participants in the intervention or control groups. Evaluation of the health course was impeded when a health module was included in social and working life orientation for the control group. In an evaluation by Perski and Gross (2004), comparison between an intervention group and a control group was impeded when the control group sought extensive professional help with improvements in health status. The results of this study can be compared with the results of the aforementioned study.

Poorer physical and mental health can be observed among women in the groups in this study, which is consistent with other studies on living conditions of recently settled immigrants, which reports that men generally self-report better health than do women. This is explained in various ways, including the existence of biological and physiological aspects, but also that there are differences in health-related behaviors and living conditions. Examples include attitudes towards working and family life and other socially conditioned factors that could entail health risks (Steel et al., 2014; Straiton et al., 2019; Swedish National Audit Office, 2018). In this study, men reported higher HRQoL at six months post-intervention, while women reported higher HRQoL postintervention, immediately after the end of the health-management course. It could be advantageous to design initiatives adapted for women over a longer period of time in order to increase and support the five health systems developed by Lindencrona et al. (2006), (attachment, safety/security, identity/roles, human rights/justice, and existential/ creation of meaning). Other reasons to support longer initiatives for women include reducing isolation. Post-intervention, the women in this study returned to their previous everyday lives in the home, while the men were more likely to enter paid work.

Labor force participation is significantly lower among women born abroad than for women born in Sweden, men born in Sweden, and men born abroad. Weak ties to the labor market are problematic for the individual, for her children, and from a public finance perspective (Delara, 2016; Llácer et al., 2007; Swedish National Audit Office, 2018). In this study, recently settled men were employed to a greater extent than the women in the intervention and control groups, both pre-intervention and at six months post-intervention. This is consistent with the results of earlier studies showing that women have a longer path to becoming active in society in relation to the labor market, as well as women's rights and opportunities (Delara, 2016; Llácer et al., 2007 ; Swedish National Audit Office, 2018). 
Subsidized work was the most common form of employment among the participants in this study, in both the intervention and control groups. In Åre, all jobs held by participants were subsidized. The "extra jobs" program was established in late 2015, aimed at goals including reinforcing labor market establishment for the long-term unemployed. People born outside Europe were over-represented among people in subsidized employment and many had no significant education (Swedish Association of Local Authorities and Regions, 2018).

Language skills are a crucial factor in social integration (Beiser \& Hou, 2001). Good communication is essential to giving and receiving equitable health and social care. Language skills are also a key factor in social participation, which is a health promotion factor (Alegria et al., 2017; Hadziabdic et al., 2014). In this study, there were many different nationalities in both intervention groups attending the same health-management course and in the control group. The number of language groups was particularly high in Strömsund, where there were 12 different nationalities, which precluded the use of language support in the health course. Consequently, information was provided and discussed in Swedish at the health course. Glossaries were compiled for each theme covered in the health course and were reviewed beforehand by the municipal coordinator and participants were prepared for the discussions in the health-management course. The participants reported that they had gained a generally better Swedish vocabulary, since they were able to practice speaking Swedish while attending the health course, and that they were able to better manage situations in society after having participated in the health-management course.

One challenge in this study was to measure HRQoL in the most reliable way possible. This study used the self-administered RAND-36 survey, which has demonstrated good reliability and validity (Orwelius et al., 2017). When self-administered surveys are used, questions related to health and health-related quality of life can be either overestimated or underestimated. This is something that cannot be precluded when self-administered surveys are used and should be considered in scientific studies (Adams et al., 2005; Duncan et al., 2001; Turk, 1999). This study used the Swedish version of the RAND-36 survey and language support was available when the participants completed the survey. The same members of staff provided identical information on all occasions when the participants filled out the survey and when work rate was registered.

\section{Conclusions}

Poorer physical and mental health could be observed among women in this study. Men were employed to a greater extent than the women and subsidized work was the most common form of employment among the participants. Participants in both groups had maintained HRQoL from pre-intervention to six months post-intervention. The results are considered to be transferable to a wider immigrant population with comparable medical, social, and societal conditions.

Further studies investigating the participants experiences of the health-managing course but also more homogenous measurements in studies for recently settled immigrants are needed. 
Acknowledgements We would like to thank all the participants for their contribution to this study. The authors would like to thank primary care and the local authorities in Berg, Strömsund and Åre, Sweden, especially Rut Sannemo, Agneta Westberg, Lena Esbjörnsson, Inga-Maj Persson, Anja Skålén, Lisette Hall, Louise Hamberg-Dardel, and Victoria Zubritskaya for their help in making this study possible.

Author Contribution All authors contributed to the paper. Rita Sjöström (RS), Gunilla (GK), and Lars Söderström (LS) made substantial contributions to conception and design of the paper. RS was responsible for the data acquisition. RS and LS processed the data. The paper was written by RS and GK. All authors discussed the results, commented on the manuscript, and gave final approval of the version to be published.

Funding Open access funding provided by Umea University. This work is supported by the The Coordination Agency of the Region of Jämtland, Sweden, and the Unit of Research, Education and Development, Östersund Hospital, Region Jämtland Härjedalen, Östersund, Sweden.

Data Availability The data analyzed during the current study are available from the corresponding author on reasonable request.

\section{Declarations}

Ethics Approval Ethical approval was obtained from the Regional Ethical Review Board, Umeå (Ref. 2015/411-31Ö).

Consent to Participate All participants signed written informed consent before entering into the study. The study was approved by the Regional Ethical Review Board, Umeå (Ref. 2015/411-31Ö).

Consent for Publication Informed consent was obtained before entering into the study. The study was approved by the Regional Ethical Review Board, Umeå (Ref. 2015/411-31Ö).

Conflict of Interest The authors declare no competing interests.

Open Access This article is licensed under a Creative Commons Attribution 4.0 International License, which permits use, sharing, adaptation, distribution and reproduction in any medium or format, as long as you give appropriate credit to the original author(s) and the source, provide a link to the Creative Commons licence, and indicate if changes were made. The images or other third party material in this article are included in the article's Creative Commons licence, unless indicated otherwise in a credit line to the material. If material is not included in the article's Creative Commons licence and your intended use is not permitted by statutory regulation or exceeds the permitted use, you will need to obtain permission directly from the copyright holder. To view a copy of this licence, visit http://creativecommons.org/licenses/by/4.0/.

\section{References}

Adams, S. A., Matthews, C. E., Ebbeling, C. B., Moore, C. G., Cunningham, J. E., Fulton, J., \& Hebert, J. R. (2005). The effect of social desirability and social approval on self-reports of physical activity. American Journal of Epidemiology, 161(4), 389-398. https://doi.org/10.1093/aje/kwi054.

Alegria, M., Alvarez, K., \& DiMarzio, K. (2017). Immigration and mental health. Current Epidemiology Reports, 4(2), 145-155. https://doi.org/10.1007/s40471-017-0111-2.

Beiser, M., \& Hou, F. (2001). Language acquisition, unemployment and depressive disorder among Southeast Asia refugees: a 10-year study. Social Science \& Medicine, 53(10), 1321-1334. https://doi.org/10.1016/ s0277-9536(00)00412-3.

Delara, M. (2016). Social determinants of immigrant women's mental health. Advances in Public Health, https:// www.hindawi.com/journals/ aph/2016/9730162/. https://doi.org/10.1155/2016/9730162, 2016, 1, 11. 
Duncan, G. E., Sydeman, S. J., Perri, M. G., Limacher, M. C., \& Martin, A. D. (2001). Can sedentary adults accurately recall the intensity of their physical activity? Preventive Medicine, 33(1), 18-26. https://doi. org/10.1006/pmed.2001.0847.

Ekblad, S., \& Silove, D. (1998). Proposal for the development of mental health and psychosocial services in refugee camps: 18 August 1998. UNHCR. Paper from a mission for UNHCR.

Eriksson-Sjöö, T. (2012). Utmaningar och bemötande i flyktingmottagandet. [Challenges and treatment of refugee reception]. Malmö University, Licentiate Thesis; 2012: 3.

Eriksson-Sjöö, T. \& Ekblad, S. (2009). Stress, sömn och livskvalitet - En studie bland flyktingar $i$ SFIutbildning, lärare och handläggare i Fosie stadsdel, Malmö. [Stress, sleep and quality of life - A study among refugees in SFI language courses, teachers and administrators in the Fosie district of Malmö]. Malmö University, R\&D Report 2009:5.

Eriksson-Sjöö, T., Cederberg, M., Östman, M., \& Ekblad, S. (2012). Quality of life and health promotion intervention — a follow up study among newly-arrived Arabic-speaking refugees in Malmö, Sweden. International Journal of Migration, Health and Social Care, 3, 112-126. https://doi.org/10.1108/17479891211267302.

Forsen, L., Waaler Loland, N., Vuillemin, A., Chinapaw, M., van Poppel, M. N. M., Mokkink, L. B., van Mechelen, W., \& Terwee, C. B. (2010). Self-administered physical activity questionnaires for the elderly - a systematic review of measurement properties. Sports Medicine, 7, 601-623. https://doi.org/10.2165/ 11531350-000000000-00000.

Hadziabdic, E., Albin, B., \& Hjelm, K. (2014). Arabic-speaking migrants' attitudes, opinions, preferences and past experiences concerning the use of interpreters in healthcare: a postal cross-sectional survey. $B M C$ Research Notes, 3(7), 71. https://doi.org/10.1186/1756-0500-7-71.

Lindencrona, F. (2008). Strategies for a health promoting introduction for newly arrived refugees and other immigrants. Karolinska Institutet, Stockholm. Dissertation.

Lindencrona, F., Ekblad, S. \& Johanson Blight, K. (2006). Integration och folkhälsa - en kunskapsöversikt. [Integration and public health - a knowledge survey]. Swedish Integration Board. Accessed 3 April 2019. https://mkcentrum.se/wp-content/uploads/2019/05/folkhalsa.pdf.

Llácer, A., Zunzunegui, M. V., Amo, J., del Mazarrasa, L., \& Bolůmar, F. (2007). The contribution of a gender perspective to the understanding of migrants' health. Journal of Epidemiology and Community Health, 1(61(Suppl 2)), ii4-ii10. https://doi.org/10.1136/jech.2007.061770.

McLeroy, K. R., Bibeau, D., Steckler, A., \& Glanz, K. (1988). An ecological perspective on health promotion programs. Health Education Quarterly, 15(4), 351-377.

Orwelius, L., Nilsson, M., Nilsson, E., Wenemark, M., Walfridsson, U., Lundström, M., Taft, C., Palaszewski, B., \& Kristenson, M. (2017). The Swedish RAND-36 Health Survey - reliability and responsiveness assessed in patient populations using Svensson's method for paired ordinal data. Journal of Patient Reported Outcomes, 2(1), 4. https://doi.org/10.1186/s41687-018-0030-0.

Perski, A., \& Gross, G. (2004). Treatment of patients on long-term sick leave of stress-related problems. Results from an intervention study. Läkartidningen, 14, 1295-1298 in Swedish.

Rand Health Care. RAND-36/SF-36 and EQ5D. (2018). Accessed 7 February 2018 http://www.rand.org/ health/surveys tools/mos.html/.

Silove, D. (1999). The psychosocial effects of torture, mass human rights violations and refugee trauma: toward an integrated conceptual framework. Journal of Nervous and Mental Disease, 187(4), 200-207. https://doi.org/10.1097/00005053-199904000-00002.

Steel, Z., Marnane, C., Iranpour, C., Chey, T., Jackson, J. W., Patel, V., \& Silove, D. (2014). The global prevalence of common mental disorders: a systematic review and metaanalysis 1980-2013. International Journal of Epidemiology, 43(2), 476-493. https://doi.org/10.1093/ije/dyu038.

Straiton, M., Corbett, K., Hollander, A. C., \& Hauge, L. J. (2019). Outpatient mental healthcare service use among women with migrant background in Norway: a national register study. BMC Health Services Research, 19, 944. https://doi.org/10.1186/s12913-019-4788-4.

Swedish Association of Local Authorities and Regions (SALAR). (2018). Extratjänster i kommuner och landsting. [Extra services in municipalities and counties]. Accessed 24 April 2019. https://webbutik.skl.se.

Swedish National Audit Office (RiR). (2018). Jämställdhetsintegrering av integrationspolitiken - ett outnyttjat verktyg. [Equality integration of politics for social integration - an unexploited tool]. $\mathrm{RiR}$ 2018:33. Accessed 15 April 2019. http://www.riksrevisionen.se/rapporter/granskningsrapporter/2018/ jamstalldhetsintegrering-av-integrationspolitiken/.

Swedish National Board of Health and Welfare. (2009). Public Health Report, 2009-126-71. Edita Västra Aros. Accessed 11 February 2019. https://www.socialstyrelsen.se.

Swedish Social Insurance Agency. SUS. (2015). Accessed 4 February 2019. https://www.forsakringskassan. se/myndigheter/kommuner/sus/. 
The Coordination Agency of the Region of Jämtland (Samordningsförbundet i Jämtlands län). (2014). Samverkansförbundet/i-processriktad analys av samverkan, metoder och vektyg för hållbar integration. http://www.samjamt.se/. Accessed 6 Feb 2019.

Turk, D. C. (1999). The role of psychological factors in chronic pain. Acta Anaesthesiologica Scandinavica, 43(9), 885-888.

United Nations (1948). The Universal Declaration of Human Rights (UDHR). United Nations Dec 101948. Accessed 15 March 2019. https://www.un.org/en/universal-declatation-human-rights/.

Publisher's Note Springer Nature remains neutral with regard to jurisdictional claims in published maps and institutional affiliations. 